\title{
Effects of Nitroglycerin on Left Ventricular Function in Patients with Ischemic Heart Disease
}

\author{
Hideharu Hayashi, M.D., Akira Kobayashi, M.D., \\ Tetsuo Yamashita, M.D., Kyoichi Ishizaka, M.D., \\ Chinori Kurata, M.D., Jun Kamiya, M.D., \\ Tadashi Kamikawa, M.D., and Noboru Yamazaki, M.D.
}

\section{SUMMARY}

To evaluate the effects of nitroglycerin on left ventricular function in 27 patients with ischemic heart disease, ejection fraction (EF) was measured every 1 to $5 \mathrm{~min}$ by a nuclear stethoscope after sublingual administration of nitroglycerin $(0.3 \mathrm{mg})$.

(1) There was a good correlation between EF determined by the nuclear stethoscope and EF by left ventriculography $(r=0.80$, $\mathrm{p}<0.001$ ). (2) EF showed a rise after sublingual nitroglycerin, which was most marked at 4 to $7 \mathrm{~min}$ and returned to the control level in 20 to $25 \mathrm{~min}$. (3) There were no significant differences in the maximum percent increase in $\mathrm{EF}$ among patients with $0,1,2$ and 3 vessel disease. The maximum percent increases in EF were $34.0 \pm 10.0 \%$ in the normal contraction group, $24.0 \pm$ $8.5 \%$ in the hypokinesis group ( $\mathrm{p}<0.05$ vs the normal contraction group) and $15.2 \pm 8.5 \%$ in the akincsis group ( $<<0.01$ vs the normal contraction group, $\mathrm{p}<0.05$ vs the hypokinesis group). (4) There was a weak correlation between the maximum percent increase in EF and the changes in heart rate $(\mathrm{r}=0.49, \mathrm{p}<0.05)$ and there was an inverse correlation between the maximum percent increase in $\mathrm{EF}$ and the changes in systolic blood pressure $(\mathrm{r}=-0.65$, $\mathrm{p}<0.01$ ).

It was shown that the improvement in $\mathrm{EF}$ by sublingual nitroglycerin was greatest in the normal contraction group, somewhat less in the hypokinesis group and least in the akinesis group. The nuclear stethoscope is useful in monitoring changes in left ventricular function during intervention.

\footnotetext{
From the Third Department of Internal Medicine, Hamamatsu University School of Medicine, Hamamatsu.

Address for reprint: Hideharu Hayashi, M.D., Third Department of Internal Medicine, Hamamatsu University School of Medicine, 3600 Handa-cho, Hamamatsu 431-31, Japan.

Received for publication January 21, 1984.

Manuscript revised May 11, 1984.
} 


\section{Additional Indexing Words:}

Ejection fraction Coronary angiography Left ventriculography

TROGLYCERIN is commonly used in patients with ischemic heart disease and its effects on cardiovascular hemodynamics ${ }^{1-3)}$ and coronary blood flow ${ }^{4-6)}$ have been studied. Recently, there has been considerable interest in the effects of nitroglycerin on left ventricular wall motion in patients with ischemic heart disease. ${ }^{\text {7)-13) }}$ It has been reported that left ventricular wall motion abnormalities are a common result of ischemic heart disease $^{14), 15)}$ and that hypokinetic wall motion improved in a majority of patients, following nitroglycerin, while dyskinetic motion was unchanged and the akinetic segments had an intermediate response. ${ }^{7,10), 11)}$

We cvaluated the effects of sublingual nitroglycerin on ejection fraction (EF) in patients with normal and abnormal wall motion, using the nuclear stethoscope $\mathrm{e}^{\mathbf{1 6}), 17)}$ which is an EGG-triggered, non-imaging nuclear probe. It has been shown that there is a good correlation between EF measured by the nuclear stethoscope and by the camera-computer system. ${ }^{16), 17)}$

The present study was undertaken using the nuclear stethoscope to determine: (1) The correlation between EF measured by the nuclear stethoscope and left ventriculography, (2) serial changes in EF after sublingual administration of nitroglycerin, (3) changes in EF according to the findings of coronary angiography and left ventriculography and (4) the correlation between the changes in EF and the changes in hemodynamic parameters.

\section{Subjects and Methods}

\section{Subjects :}

Twenty-seven patients, 22 males and 5 females, with a mean age of 56 years (range 37 to 71 years) were studied. Nine patients had angina pectoris, 11 had had previous myocardial infarction and 7 had chest pain syndrome with normal coronary arteries. Coronary angiography and left ventriculography were performed in all patients and significant coronary artery disease was defined as $75 \%$ or greater stenosis of one or more of the three major coronary vessels. Eight had one-vessel disease, 9 had two-vessel disease and 3 had three-vessel disease. Seven had normal coronary arteries. According to left ventriculography, 7 had normal contraction, 10 had hypokinesis and 10 had akinesis.

None of the patients had clinical or radiological evidence of heart failure and none had used sublingual nitroglycerin, long-acting nitrates or calcium 
antagonists for at least 12 hours prior to the study.

\section{Methods :}

Left ventricular function was measured with a nuclear stethoscope (Bios Inc., USA), which is a simple, mobile, non-imaging nuclear probe with an integrated microcomputer. After administration of $15 \mathrm{mCi}$ of technetium$99 \mathrm{~m}$ human serum albumin, the probe was placed in front of the chest in the $20-40^{\circ}$ left anterior oblique position with a $10-20^{\circ}$ caudal tilt. Ejection fraction (EF) was measured using the ventricular function mode with an acquisition period of $60 \mathrm{sec}$.

Fig. 1 shows the average left ventricular volume curve displayed after background substraction. Here, the cursors indicate end-diastolic and end-

\section{before NTG}

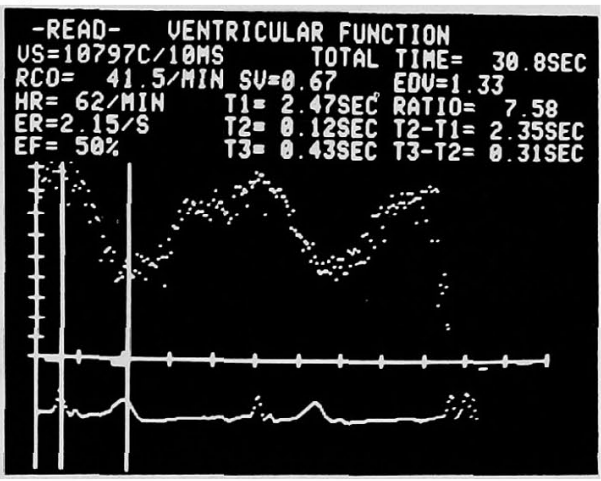

\section{5 min after NTG}

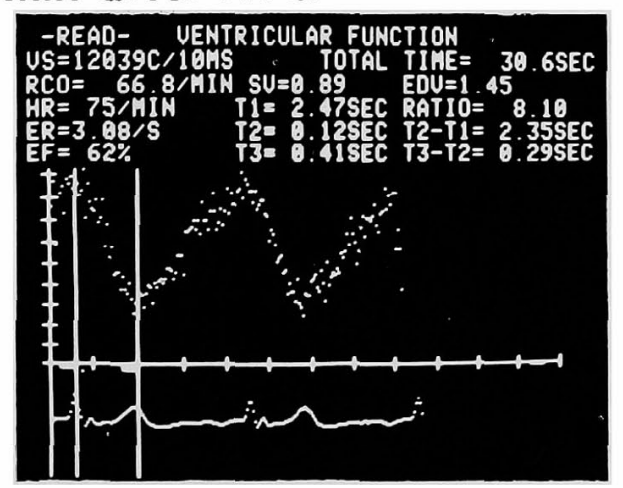

Fig. 1. The average left ventricular volume curve displayed after background substraction. Two cursors indicate end-diastolic and end-systolic count rate. EF and other parameters are shown at the upper part of the photograph. Abbreviation: $\mathrm{NTG}=$ nitroglycerin. 


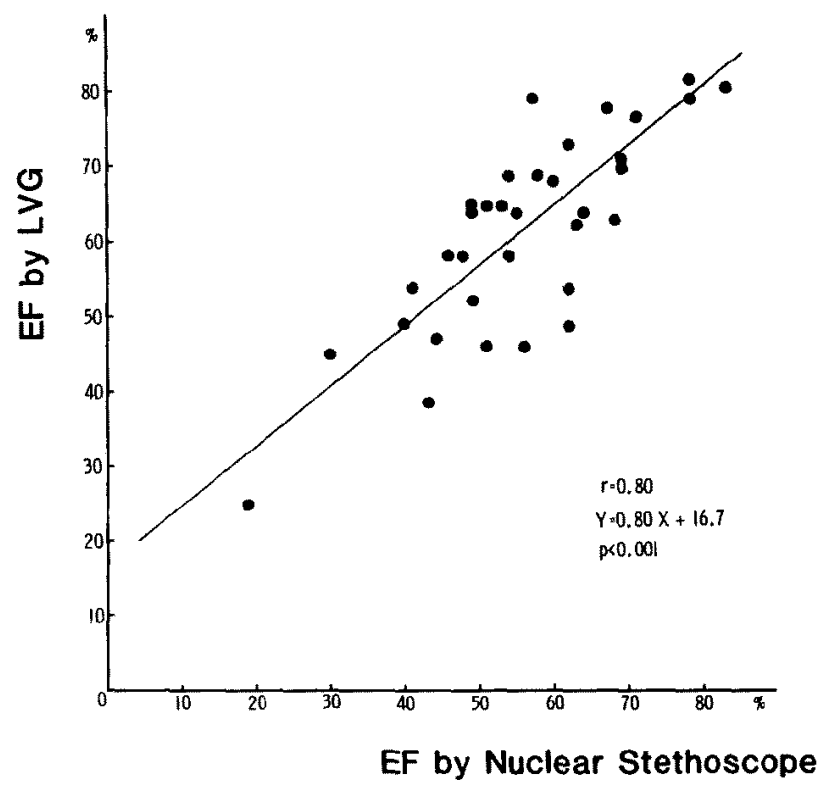

Fig. 2. The correlation between EF by the nuclear stethoscope and EF by left ventriculography in 35 patients with ischemic heart disease. Abbreviation: $L V G=$ left ventriculography.

systolic count rates. EF and other parameters are automatically computed from this curve. As shown in this curve, EF increased from 50\% to $62 \%$ 5 min after administration of sublingual nitroglycerin.

After sublingual administration of $0.3 \mathrm{mg}$ of nitroglycerin, EF by the nuclear stethoscope, blood pressure and heart rate were measured serially every 1 to $5 \mathrm{~min}$ for $30 \mathrm{~min}$.

All data are reported as mean $\pm \mathrm{SD}$ except those in Fig. 3, which are shown as mean $\pm \mathrm{SEM}$ and compared using Student's t-test. A p value of less than 0.05 was considered significant.

\section{Results}

(1) Comparison of left ventricular EF by the nuclear stethoscope and left ventriculography

EF was measured in 35 patients by both the nuclear stethoscope and left ventriculography (Fig. 2). There was a close correlation between the two methods with a correlation coefficient of $0.80(p<0.001)$.

(2) Serial changes in $\mathrm{EF}$ after sublingual nitroglycerin

Fig. 3 shows the percent increase in EF after sublingual administration of nitroglycerin. Based upon ventricular contraction determined by left ven- 


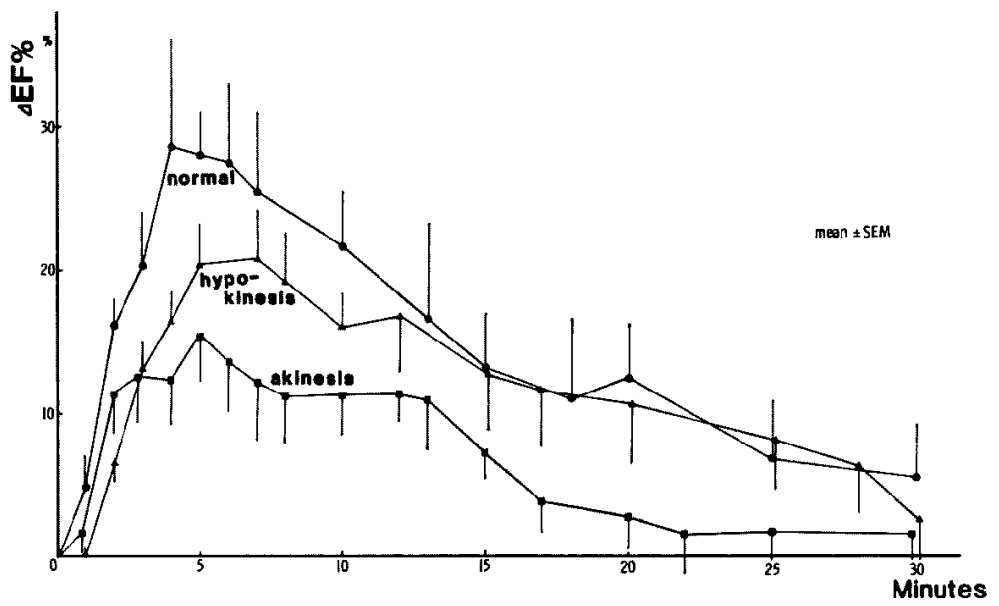

Fig. 3. The percent increase in $\mathrm{EF}(\Delta \mathrm{EF} \%$ ) after sublingual administration of nitroglycerin. Patients are divided into 3 groups according to ventricular contraction by left ventriculography.

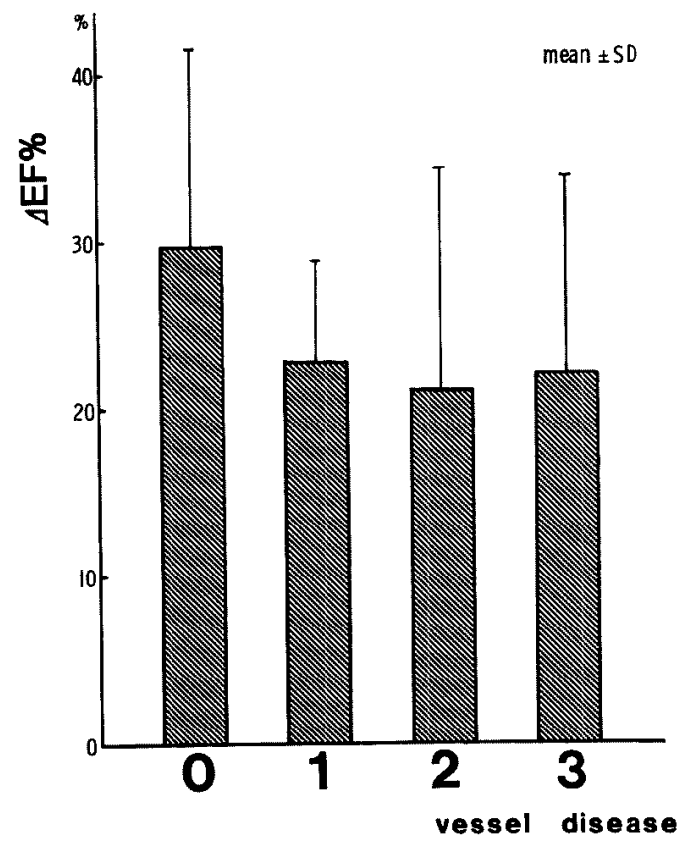

Fig. 4. The maximum percent increase in EF ( $\Delta \mathrm{EF} \%$ ) according to the findings of coronary angiography.

triculography, 3 groups of patients showed a rise in EF, which was most marked at 4 to $7 \mathrm{~min}$. EF returned to the control level in 20 to $25 \mathrm{~min}$ after sublingual administration of nitroglycerin.

(3) Changes in EF according to the findings of coronary angiography 


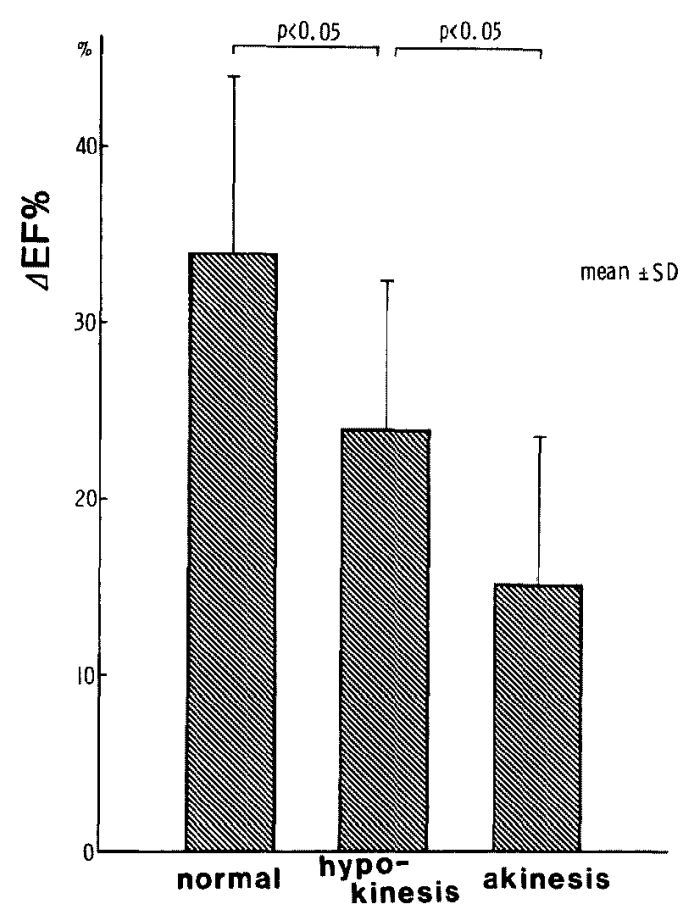

Fig. 5. The maximum percent increase in $\mathrm{EF}(\Delta \mathrm{EF} \%)$ according to the findings of left ventriculography.

and left ventriculography

Following administration of sublingual nitroglycerin, the mean EF improved from $56.0 \pm 6.6 \%$ to $72.6 \pm 9.6 \%(\mathrm{p}<0.001)$ in 0 -vessel disease, from $54.6 \pm 13.9 \%$ to $67.5 \pm 18.5 \%(\mathrm{p}<0.001)$ in 1 -vessel disease, from $53.1 \pm$ $12.0 \%$ to $65.2 \pm 20.2 \%(\mathrm{p}<0.01)$ in 2 -vessel disease and from $46.3 \pm 5.0 \%$ to $56.3 \pm 5.1 \%$ (n.s.) in 3-vessel disease. The maximum percent increases in $\mathrm{EF}$ were $29.8 \pm 11.8 \%, 22.9 \pm 6.0 \%, 21.1 \pm 13.3 \%$ and $22.1 \pm 11.8 \%$, in $0,1,2$ and 3 vessel disease, respectively (Fig. 4). There were no significant differences in the maximum percent increase in $\mathrm{EF}$.

The mean EF improved from $52.9 \pm 8.5 \%$ to $70.3 \pm 10.7 \%(\mathrm{p}<0.001)$ in the normal contraction group, from $57.4 \pm 9.6 \%$ to $71.1 \pm 14.9 \% \quad(\mathrm{p}<0.001)$ in the hypokinesis group and from $48.7 \pm 11.5 \%$ to $56.8 \pm 16.4 \%(p<0.01)$ in the akinesis group. The maximum percent increases in EF were $34.0 \pm$ $10.0 \%$ in the normal contraction group, $24.0 \pm 8.5 \%$ in the hypokinesis group ( $<<0.05$ vs the normal contraction group) and $15.2 \pm 8.5 \%$ in the akinesis group ( $\mathrm{p}<0.01$ vs the normal contraction group, $\mathrm{p}<0.05$ vs the hypokinesis group) (Fig. 5).

(4) The correlation between the maximum percent increase in EF and 

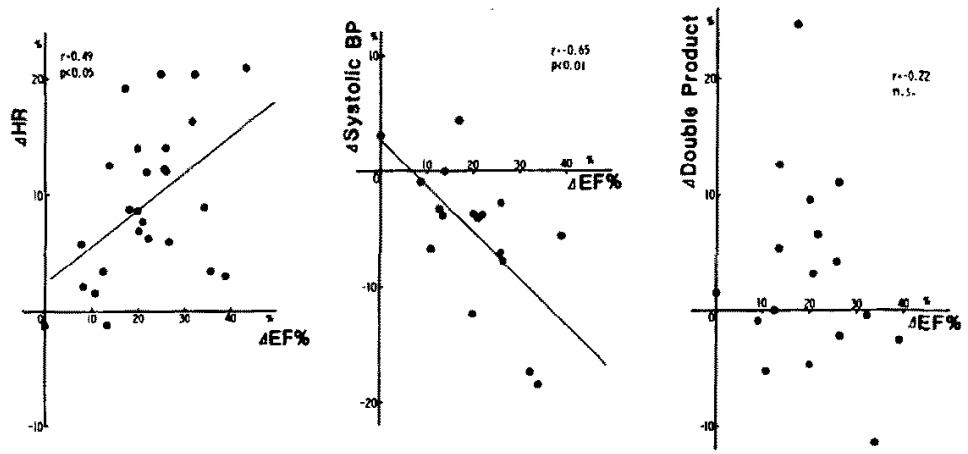

Fig. 6. The correlation between the maximum percent increase in EF $(\Delta \mathrm{EF} \%)$ and the changes in heart rate $(\Delta \mathrm{HR})$, systolic blood pressure ( $\Delta$ systolic BP) and double product (Jdouble product).

the changes in hemodynamic parameters

There was a weak correlation between the maximum percent increase in $\mathrm{EF}$ and the changes in heart rate $(\mathrm{r}=0.49, \mathrm{p}<0.05)$ and there was an inverse correlation between the maximum percent increase in $\mathrm{EF}$ and the changes in systolic blood pressure $(r=-0.65, p<0.01)$. There was no correlation between the maximum percent increase in EF and the changes in double product ( $r=-0.22$, n.s.) (Fig. 6).

\section{Discussion}

In this study, we have used the nuclear stethoscope to study the rapid sequence of events during sublingual nitroglycerin administration. The nuclear stcthoscope has the obvious advantages of offering rapid bedside measurement of left ventricular function and monitoring changes in left ventricular performance non-invasively during intervention with cardiac drugs.

We have found, as have other investigators, ${ }^{91,101,121,18}$ that in patients with normal coronary artery and ischemic heart disease, nitroglycerin can improve EF while the patient is at rest. Our results indicate that the improvement in EF following administration of nitroglycerin was greatest in the normal contraction group, somewhat less in the hypokinesis group and least in the akinesis group. The improvement in global left ventricular ejection fraction might be a result of by the improvement in segmental wall motion, as Shah et al $^{19}$ have reported. Helfant ${ }^{\text {? }}$ and others ${ }^{10), 11 /}$ have also reported that most of the improvement in ventricular wall motion occurred in the hypokinetic segments and that frank dyskinesis was not improved by nitroglycerin. EF in the hypokinesis group might have improved as a result of 
the remaining areas of still functionally reversible myocardium ${ }^{201}$ possessing functional contractile reserve and being capable of responding to nitroglycerin administration. Bodenheimer et $\mathrm{al}^{20)}$ have reported that histopathologically, the improved area of myocardium after nitroglycerin showed less than $10 \%$ muscle loss.

The possible mechanisms of action of nitroglycerin have been reported as improvement in oxygen delivery to ischemic tissue by increasing total myocardial blood flow ${ }^{2,4)}$ or producing a redistribution of $f^{\left(0 w^{5), 6)}\right.}$ and a reduction in myocardial oxygen demand by decreasing preload $^{1,3)}$ and afterload. ${ }^{21,22)}$ The mechanism responsible for the beneficial effects of nitroglycerin $^{23)}$ cannot be elucidated from the findings of the present investigation as the myocardial blood flow and preload were not measured in this study. There was an inverse correlation between the maximum percent increase in $\mathrm{EF}$ and the changes in systolic blood pressure in our investigation and this observation suggests that the improved ventricular function could have been secondary, at least in part, to the effects of nitroglycerin on afterload.

\section{ReFERENGES}

1. Najmi M, Griggs DM Jr, Kasparian H, Novack P: Effects of nitroglycerin on hemodynamics during rest and exercise in patients with coronary insufficiency. Circulation 35: 46, 1967

2. Vatner SF, Higgins CB, Millard RW, Franklin D: Direct and reflex effects of nitroglycerin on coronary and left ventricular dynamics in conscious dogs. J Clin Invest 51 : 2872, 1972

3. Strauer BE, Scherpe A: Ventricular function and coronary hemodynamics after intravenous nitroglycerin in coronary artery disease. Am Heart J 95: 210, 1978

4. Marchetti GV, Merlo L, Antognetti RM: The effects of nitroglycerin on the coronary blood flow and oxygen consumption of the myocardium in anesthetized dogs. Am J Cardiol 13: 51,1964

5. Cohn PF, Maddox D, Holman BL, Markis JE, Adams DF, See JR: Effects of sublingually administered nitroglyccrin on regional myocardial blood flow in patients with coronary disease. Am J Cardiol 39: 672, 1977

6. Mehta J, Pepine CJ: Effect of sublingual nitroglycerin on regional flow in patients with and without coronary disease. Circulation 58: 803, 1978

7. Helfant RH, Pine R, Meister SG, Fcldman MS, Trout RG, Banka VS: Nitroglycerin to unmask reversible asynergy. Correlation with coronary bypass ventriculography. Circulation 50: 108, 1974

8. Banka VS, Bodenheimer MM, Helfant RH: Determinants of reversible asynergy. Effect of pathologic $Q$ waves, coronary collaterals, and anatomic location. Circulation 50: 714, 1974

9. McAnulty JH, Hattenhauer MT, Rösch J, Kloster FE, Rahimtoola SH: Improvement in left ventricular wall motion following nitroglycerin. Circulation 51 : 140, 1975

10. Dumesnil JG, Ritman EL, Davis GD, Gau GT, Rutherford BD, Fryc RL: Regional left ventricular wall dynamics before and after sublingual administration of nitroglycerin. Am J Cardiol 36: 419, 1975

11. Henning H, Crawford MH, Karliner JS, O'Rourke RA: Beneficial effects of nitroglycerin on abnormal ventricular wall motion at rest and during exercise in patients with previous myo- 
cardial infarction. Am J Cardiol 37: 623, 1976

12. Salcl AF, Bcrman DS, DeNardo GL, Mason DT: Radionuclide assessment of nitroglycerin influence on abnormal left ventricular segmental contraction in patients with coronary heart disease. Circulation 53: 975, 1976

13. Borer JS, Bacharach SL, Green MV, Kent KM, Johnston GS, Epstein SE: Effects of nitroglycerin on exercise-induced abnormalities of left ventricular regional function and ejection fraction in coronary artery disease. Assessment by radionuclide cineangiography in symptomatic and asymptomatic patients. Circulation 57: 314, 1978

14. Herman MV, Heinle RA, Klein MD, Gorlin R: Localized disorders in myocardial contraction. Asynergy and its role in congestive heart failure. New Engl J Med 277: 222, 1967

15. Ramanathan KB, Bodenheimer MM, Banka VS, Helfant RH: Severity of contraction abnormalities after acute myocardial infarction in man: response to nitroglycerin. Circulation 60: 1230,1979

16. Wagner HN Jr, Wake R, Nickoloff E, Natarajan TK: The nuclear stethoscope: a simple device for generation of left ventricular volume curves. Am J Cardiol 38: 747, 1976

17. Wagner HN Jr, Rigo P, Baxter RH, Alderson PO, Douglass KH, Housholder DF : Monitoring ventricular function at rest and during exercise with a nonimaging nuclear detector. Am J Cardiol 43: 975,1979

18. Slutsky R, Curtis G, Battler A, Froelicher V, Ross J Jr, Gordon D, Ashburn W, Karliner J : Effects of sublingual nitroglycerin on left ventricular function at rest and during spontancous angina pectoris: assessment with a radionuclide approach. Am J Cardiol 44: 1365, 1979

19. Shah R, Bodenheimer MM, Banka VS, Helfant RH: Nitroglycerin and ventricular performance. Differential effect in the presence of reversible and irreversible asynergy. Chest $\mathbf{7 0}$ : 473,1976

20. Bodenheimer MM, Banka VS, Hermann GA, Trout RG, Pasdar H, Helfant RH: Reversible asynergy. Histopathologic and electrographic correlations in patients with coronary artery disease. Girculation 53: 792, 1976

21. Greenberg H, Dwyer EM Jr, Jameson AG, Pinkernell BH: Effects of nitroglycerin on the major determinants of myocardial oxygen consumption. An angiographic and hemodynamic assessment. Am J Cardiol 36: 426, 1975

22. McEwan MP, Berman ND, Morch JE, Feiglin DH, McLaughlin PR: Effects of intravenous and intracoronary nitroglycerin on left ventricular wall motion and perfusion in patients with coronary artery disease. Am J Cardiol 47: 102, 1981

23. McGregor M: The nitrates and myocardial ischemia. Circulation 66: 689, 1982 